\title{
Quantitative study of force sensing while drilling trabecular bone in oral implant surgery
}

\author{
Mohammad Aimaduddin Atiq BIN KAMISAN*, Hideaki KINOSHITA**, Fumiya NAKAMURA*** \\ Shinya HOMMA****, Yasutomo YAJIMA****, Satoru MATSUNAGA*****, Shinichi ABE***** and \\ Naoki TAKANO*** \\ *Graduate School of Science and Technology, Keio University \\ 3-14-1 Hiyoshi, Yokohama, Kanagawa 223-8522, Japan \\ E-mail: a.atiq@keio.jp \\ **Department of Material Science, Tokyo Dental College, 2-9-18 Misaki-cho, Chiyoda, Tokyo, Japan \\ ${ }^{* * *}$ Department of Mechanical Engineering, Keio University

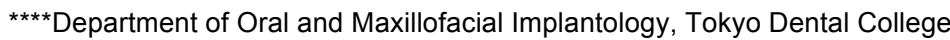

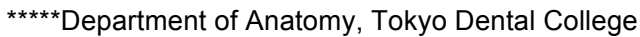

Received 6 October 2015

\begin{abstract}
A survey done recently showed that almost 30 percent of the accidents occurred during oral implant surgery were concerned with the mandibular canal in the trabecular bone region and most of them were related to the drilling process. One of the reasons known is due to the clinicians' lack of knowledge and experience. In order to overcome the problem, through the educational approach, we proposed and developed a new system mainly for dental colleges' students, by focusing on drilling the mandibular trabecular bone. The system comes in the form of an oral implant surgery training simulator that enables student to sense the reaction force during drilling. The developed system was then evaluated by expert clinicians and dental college's students. A total of 8 clinicians and 24 students tested all three samples of drilling force database. The clinicians were asked to describe the drilling force based on a stiffness scale while the students are required to drill two samples first before drilling the third sample. They were asked to sketch the third samples based on the comparison of previous samples. Based on the evaluation done, it was found that the quantification of force sensed during drilling could be derived from the combination of drilling force and speed obtained through the relative value of comparison with the previous or accumulated experience of drilling. The results of this study also indicate that the oral implant surgery training simulator could help students learn the difference of drilling force sense dependent on the bone quality through repeated usage and practices.
\end{abstract}

Key words : Oral implant, Drilling force, Drilling speed, Force sensed, Trabecular bone, Mandible

\section{Introduction}

For over 30 years, oral implant surgery is one of many treatments for tooth's deficiency (Albrektsson, et al., 2008). It particularly consists of the jawbone drilling process and implanting artificial crown. Inside the jawbone there exists a mandibular canal that holds our nerves and blood vessel. If the drill penetrated through the mandibular canal, serious problem such as trauma might occur. Japan Academy of Maxillofacial Implants had done a survey between 2009 and 2011 regarding the serious problem that occurred in oral implant surgery. From a total of about 421 cases reported, about 30 percent of the accidents were concerned with the nerves damage in the mandibular canal and 3/4 out of those estimated value are related with the drilling process in the oral implant surgery.

Chrcanovic et al. (2014) suggested that one of the reasons for oral implant failures is the doctor's own lack of knowledge and experience. Research finding by a few studies on bone drilling and oral implant also points toward the same conclusion (Augustin et al., 2008; Kim et al., 2010; Limbert et al., 2010; Melo et al., 2006; Temmerman et al., 2015). Furthermore, according to De Bruyn et al. (2009) and Ucer et al. (2014), dental colleges and universities rarely 
include the syllabus about dental implant in their education system especially during the undergraduate years but the number has started to increase by the year (Donos et al., 2009; Kroeplin and Strub, 2011; Mattheos et al., 2009, 2014). Moreover, various initiatives had been done to overcome this problem such as introduction of haptic devices and the use of detailed polymeric model (Chen et al., 2010, 2012; Kusumoto et al., 2006; Rhienmora et al., 2010; Zheng et al., 2012, 2013).

Despite of the haptic device available today, most of them are readily equipped with surgical tools or mock tools that are not actually usable in an actual surgery. The feeling might be different than holding the real tools for surgery. In the case of the detailed model, it only provides one type of reaction force or tactile sensation while drilling and it is a destructive technique making it quite expensive. As a solution, we developed an oral implant surgery training simulator that enable the user to use a real handpiece and motor unit used in an actual surgery (Kinoshita et al., 2016).

Compared with the training simulator that only focus on the drilling process, the haptic devices available provide a wide range of oral treatment for training and gives a qualitative value of tactile sensation with reaction force feedback (Zheng et al., 2013). The tactile sensation can be considered as the force sensed in the tip of the doctor's finger during drilling or considered relatively as drilling force. There are a number of studies considering the drilling force done by Sugaya (1990) and Friberg et al. (1995). In this study, we consider the drilling force as the reaction force obtained from drilling the trabecular bone and the value is based on the numerical procedure done. However, to the best of the authors' knowledge, no research has been carried out to study on the force sensed quantitatively and defining them especially in oral implant surgery. In the previous work (Kinoshita et al., 2016), the simulator was evaluated by only a few experienced dentists and mainly focuses on the characteristic felt during drilling. Therefore, the present study aims at quantifying the drilling force sensed in oral implant surgery based on the evaluation done on the developed oral implant surgery training simulator. The findings of this study will help improve the education system by giving a deeper understanding of drilling force sensed during surgery and the also the information on bone quality that is closely related to the drilling process.

\section{Material and methods}

\subsection{Oral implant surgery training simulator}

The oral implant surgery training simulator was developed in order to teach the correlation between the drilling force and the micro-architecture of trabecular bone for a variety of patients (Kinoshita et al., 2016). An overview of the simulator is shown in Fig 1(a). It consists of a control box that controls the force-sensible device which contains an actuator and load cell, the motor unit which controls the rotational speed of the drill, drilling force database, laptop PC and display monitor for a user. The load cell measures the force given by the user and moves the actuator according to the drilling force database. The usage of the training simulator requires the user to use their own handpiece that is used in an actual surgery. This way, the user could sense the reaction force, sound and vibration of a real handpiece making it feels closer to a real surgery. The simulator uses real handpiece and motor unit used in actual surgery, but instead of using a real drill, the simulator requires the usage of decentering jig as shown in Fig. 1(b). The jig is able to imitate the slight vibration during drilling. Fig. 1(c) shows how an experienced clinician using the oral implant surgery training simulator by putting the handpiece on top of the white piece of the force-sensible device.

(a)

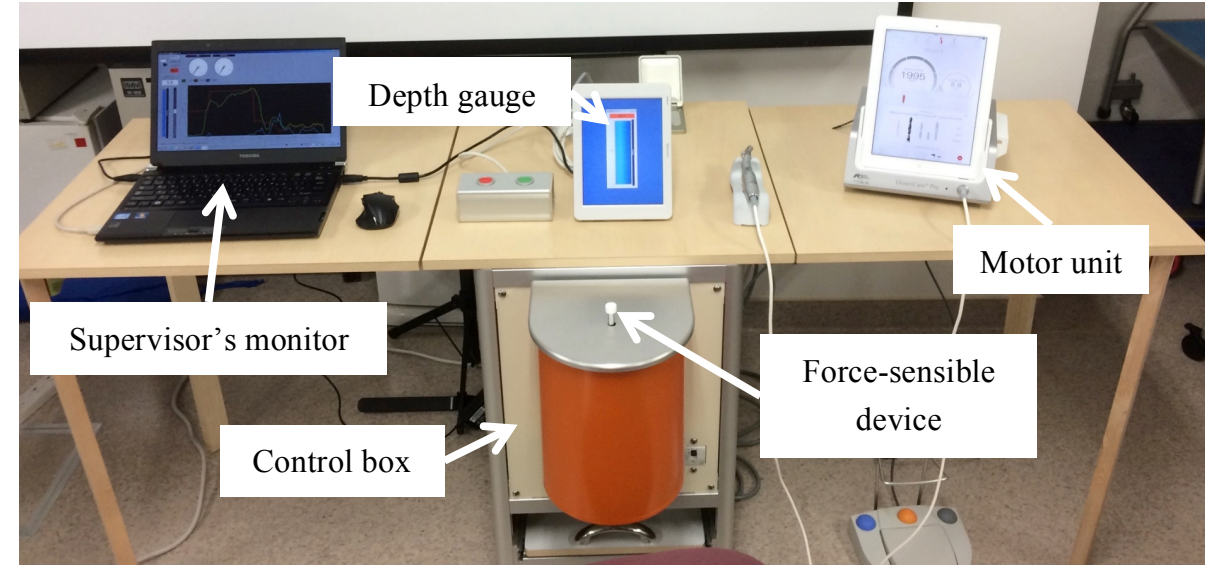

(b)

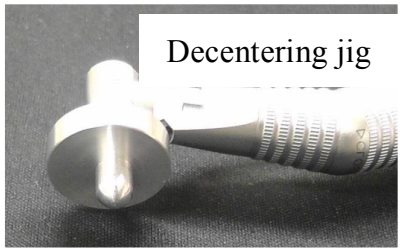

(c)

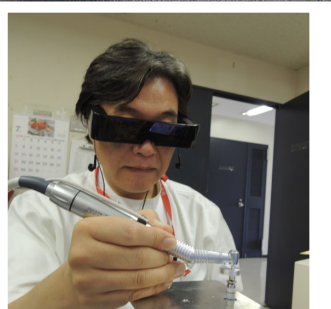

Fig. 1 (a) Outline of the oral implant surgery training simulator. (b) A decentering jig is instead of an actual drill. (c) An experienced clinician using the training simulator. 


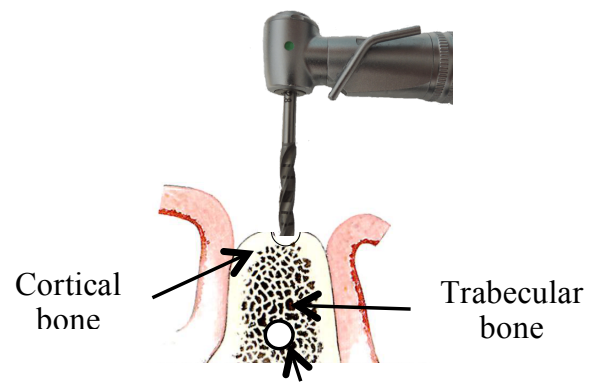

Mandibular canal

(a) Overview of the simulator database

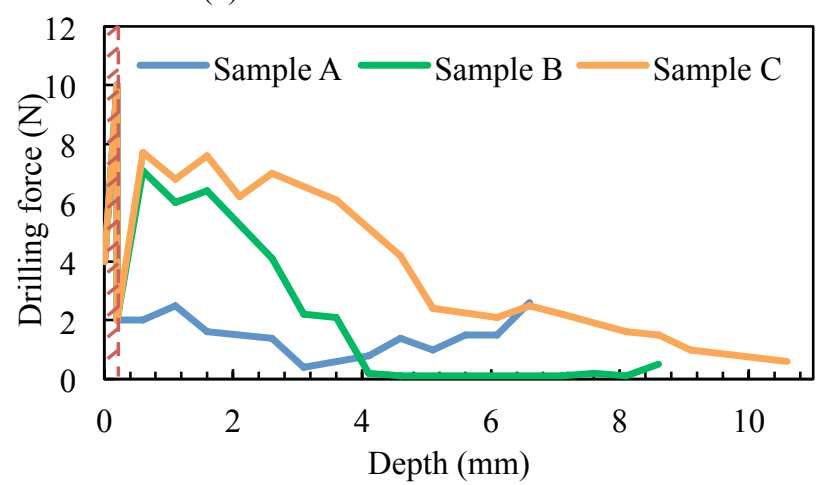

(c) Required drilling force for each sample

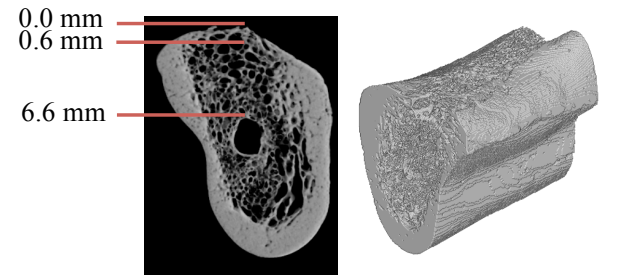

(i) Sample A

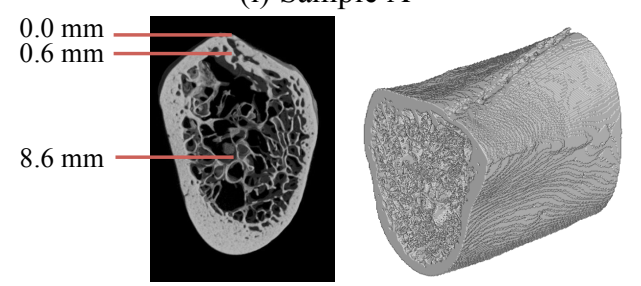

(ii) Sample B

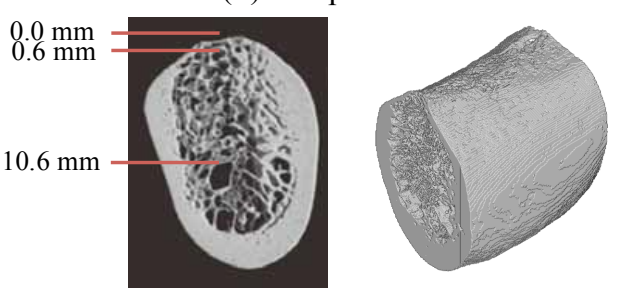

(iii) Sample C

(b) Micro-CT images of each sample with their 3D model

Fig. 2 (a) Overview of the simulator database. Only the trabecular bone region is calculated. For the remaining cortical part of the bone, which is about 0 to $0.6 \mathrm{~mm}$ of depth is calibrated based on experimental measurement. (b) The 3D model of each sample based on their micro-CT images. (c) The result of the numerical procedures.

The software part of the simulator is actually a drilling force database that was calculated using sequential linear static three-dimensional finite element analysis (FEA) on micro-CT images taken from different samples of cadaver. The drilling process is a highly nonlinear problem, but many processes remained unknown so we simplified the problem taking into account the trabecular bone architecture and excluding the dynamic effects of the drill. Fig. 2(a) shows an overview of the simulator database. The FEA were applied to the trabecular bone region but the force in the cortical bone region was adjusted based on the expert's experiences and experimental calibration. The cross section of the model extracted from micro-CT images for the calculation process can be seen in Fig 2(b). The numerical procedures were only done for the drilling force in the trabecular bone region (Tawara et al., 2015). Note that the drilling force calculated and obtained is based on the reaction force on the tip of the drill while drilling along to the drilling axis. The torque value was also neglected since there was not a high correlation with the drilling force (Sugaya, 1990). In this study we used three kinds of samples obtained from different individuals and implemented them in the training

The calculated drilling force database was also calibrated in order to ensure confidence and reliability by doing an experimental measurement of drilling force on a fresh cadaver. For the calibration, expert clinician performed three cases of the drilling process in an oral implant surgery. This includes the normal drilling, perforation of mandibular canal in the trabecular bone region and also the perforation of lingual side of the cortical bone. The value shown in Fig. 2(c) is until the depth of the mandibular canal. Notice that the high value in the top part (marked region) is based on the calibrated value. All samples are calibrated with $0.6 \mathrm{~mm}$ of cortical bone on the top part of the mandible. Note that the experiments and numerical analyses using cadavers were approved by the Ethics Committee of Tokyo Dental College.

\subsection{Evaluation of calibrated drilling force by experienced clinicians}

A total of 8 clinicians that have experience on oral implant surgical procedures tested and evaluated the samples from the drilling force database. Firstly, they were given a detailed explanation of the system of the training simulator and its database. They were shown the micro-CT images of the samples and the target depth that need to be drilled, which was located $1 \mathrm{~mm}$ above the depth of the mandibular canal. Next, the drilling simulation was done using the 
developed oral implant surgery training simulator. During the entire simulation, the information on the supervisor's monitor was hidden from the clinicians' view. The information of required drilling force based on the numerical procedure explain earlier, and their input force and speed was only revealed after the simulation was done, Then they are asked to mark the stiffness felt of the samples tested on a stiffness scale based on their experiences of handling actual surgical procedure. Furthermore, the clinicians were asked to give their overall impression of the developed oral implant surgery training simulator.

\subsection{Evaluation by dental college' students}

The students' evaluation was done during their problem-based learning (PBL) class for fifth grade students, which is a class set up to teach students learn more about the surgical procedure in oral treatment especially the oral implant surgery. 24 students took part in the evaluation and tested the samples from the drilling force database. The students were firstly given an in depth explanation of the trabecular bone region of a jawbone and the system of the training simulator. They were also shown the micro-CT images of the two samples, namely Sample A and Sample B, their required drilling force and the target depth that needs to be drilled. Then they were asked to drill the two samples, Sample A and B respectively. Similar with the clinicians' evaluation, the drilling simulation was done using the training simulator and the same information was hidden from the students' view. After each drilling simulation, the students were asked the feeling of stiffness for each sample and try to compare it with one another. Next, the students were shown a different third sample, namely Sample C. Differs from Sample A and B, only the micro-CT images of the sample and the target depth were shown to the students. After the simulation, the students were asked about Sample $\mathrm{C}$ stiffness in comparison with Sample A and B. They were then required to sketch the drilling force curve on a PC using developed software by comparing it with the previous two samples. The drawn sketch was finally converted into a Microsoft Excel file. The results of the evaluation of their sketch is described and derived based on characteristics of Sample C. Moreover, they were also asked to give their overall impression of the developed training simulator.

\section{Results}

Fig 2(c) illustrates the calculated drilling force database of Sample A, B, and C with the calibrated value based on the experiment on fresh cadaver (Kinoshita et al., 2016). As the figure shows, Sample A requires a smaller drilling force in the depth of less than about $4 \mathrm{~mm}$. This shows that Sample A is softer in the upper region than any other sample. In contrast, Sample C requires a much higher amount of drilling force showing its stiffness. Interestingly, in the lower region, which is more than $5 \mathrm{~mm}$ of depth, Sample B requires the least amount of drilling force showing its softness than any other sample. These illustrate the intra-individual differences as the amount required for drilling the trabecular bone differs in each depth for every sample. Experienced clinicians and students then evaluated these three samples.

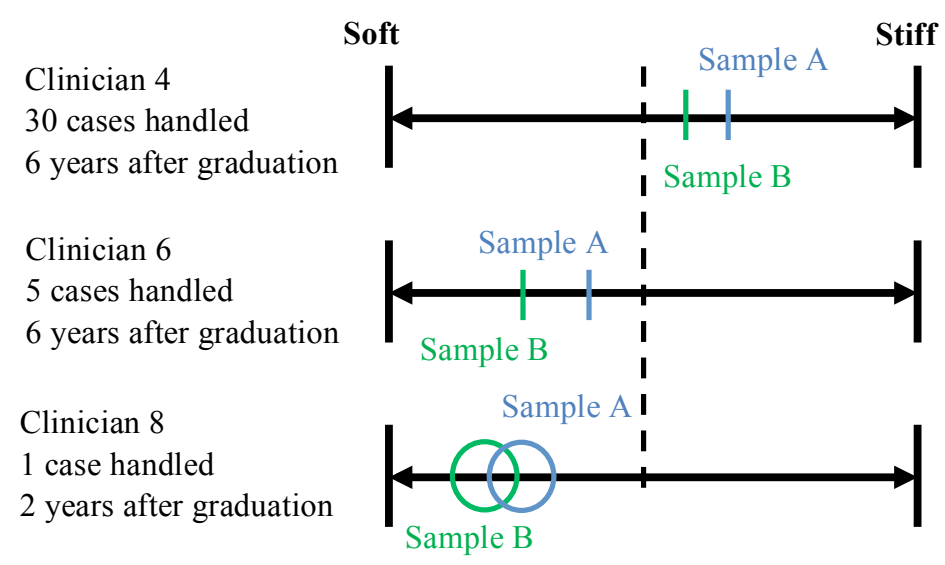

Fig. 3 Result from the clinicians' evaluation. Only three clinicians' results are shown for comparison. The stiffness felt the same for each clinician when comparing between Sample A and B but interestingly, the overall stiffness shifted to be stiffer as more experienced gained by the clinician. 
Bin Kamisan, Kinoshita, Nakamura, Homma, Yajima, Matsunaga, Abe and Takano, Journal of Biomechanical Science and Engineering, Vol.11, No.3 (2016)

Table 1 Result of the students' evaluation

\begin{tabular}{|c|c|c|c|c|c|c|c|c|c|}
\hline 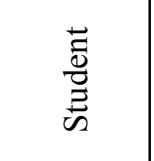 & $\begin{array}{c}\text { Perforation } \\
* 1\end{array}$ & $\begin{array}{c}\text { Force } \\
\text { difference } *^{2}\end{array}$ & $\mid \begin{array}{c}\text { Difference } \\
\text { of } 5 \mathrm{~N}^{* 3}\end{array}$ & $\begin{array}{c}\text { Big } \\
\text { drop }^{* 4}\end{array}$ & $\begin{array}{c}\text { Comparison } \\
\text { with } \\
\text { Sample B } *^{5}\end{array}$ & $\begin{array}{l}\text { Comparison } \\
\text { with } \\
\text { Sample } A^{* 6}\end{array}$ & Zigzag*7 & $\begin{array}{l}\text { Zigzag } \\
\text { value } \\
\text { around } \\
7 \mathrm{~N}^{8}\end{array}$ & $\begin{array}{l}\text { Slight } \\
\text { rise }^{* 9}\end{array}$ \\
\hline 1 & 0 & 0 & 0 & & 0 & & & & \\
\hline 2 & 0 & 0 & & & 0 & & 0 & & \\
\hline 3 & 0 & 0 & 0 & & 0 & & 0 & 0 & \\
\hline 4 & 0 & 0 & 0 & & 0 & & 0 & 0 & \\
\hline 5 & 0 & 0 & 0 & 0 & 0 & & & & \\
\hline 6 & 0 & 0 & 0 & 0 & 0 & & 0 & 0 & \\
\hline 7 & 0 & 0 & 0 & 0 & 0 & 0 & $\Delta$ & & 0 \\
\hline 8 & 0 & 0 & 0 & 0 & 0 & & 0 & 0 & 0 \\
\hline 9 & 0 & 0 & 0 & 0 & 0 & 0 & & & \\
\hline 10 & 0 & 0 & 0 & 0 & 0 & 0 & & & \\
\hline 11 & 0 & $\triangle$ & & & & 0 & & & 0 \\
\hline 12 & 0 & 0 & 0 & 0 & 0 & 0 & $\triangle$ & 0 & \\
\hline 13 & 0 & 0 & & & & & & & \\
\hline 14 & 0 & 0 & 0 & 0 & 0 & 0 & 0 & 0 & \\
\hline 15 & 0 & 0 & 0 & & 0 & 0 & & & 0 \\
\hline 16 & 0 & 0 & 0 & 0 & 0 & 0 & & & 0 \\
\hline 17 & 0 & 0 & 0 & 0 & 0 & 0 & $\triangle$ & & 0 \\
\hline 18 & 0 & 0 & 0 & 0 & 0 & 0 & & & 0 \\
\hline 19 & 0 & 0 & 0 & 0 & 0 & & & & \\
\hline 20 & 0 & 0 & 0 & & 0 & & 0 & & \\
\hline 21 & 0 & 0 & 0 & 0 & 0 & 0 & & & \\
\hline 22 & 0 & & & & & & 0 & & 0 \\
\hline 23 & 0 & 0 & & & & & 0 & & \\
\hline 24 & 0 & 0 & 0 & & 0 & & & & \\
\hline $\begin{array}{c}\text { Percentage } \\
(\%)\end{array}$ & 100.0 & 91.7 & 79.2 & 54.2 & 83.3 & 45.8 & 37.5 & 25.0 & 33.3 \\
\hline
\end{tabular}

Legend $\quad 0$ - Able to recognize $\quad \Delta$ - Somewhat able to recognize

Remarks *1 Perforation of cortical bone at the upper region right before entering the trabecular bone region

*2 The difference of force between the upper region and the lower region

*3 Difference of force for the upper and lower region is about $5 \mathrm{~N}$

*4 Sudden drop of required drilling force in about $2 \mathrm{~mm}$ of depth

*5 Required force for the upper region is higher than Sample B

*6 Required force for the lower region is smaller than Sample A

*7 Slight force change in the upper region

*8 The slight force change value is around $7 \mathrm{~N}$ with a difference of $\pm 1 \mathrm{~N}$

*9 A slight rise of required force after the big drop
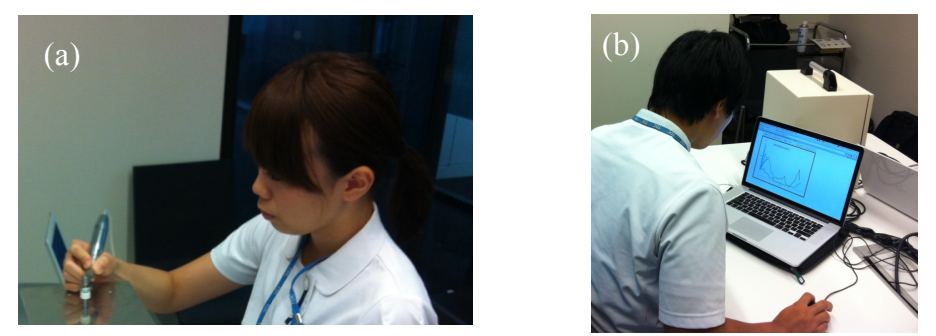

Fig. 4 (a) One of the students doing the drilling simulation. (b) After that they are required to sketch the force curve of Sample C. The sketch is drawn using the developed software. The software could translate the curve drawn into points in Microsoft Excel format that enable us to recognize the sketch quantitatively. 
During the clinicians' evaluation, most of the clinicians only tested two samples, which is Sample A and B. All of the clinicians could differentiate the stiffness for each sample and accordingly marked them in the stiffness scale. For all of them, the stiffness felt marked in the scale were mostly in the lower region of the trabecular bone as they felt that Sample A is much stiffer than Sample B as shown in Fig. 3. By comparing the result with the drilling force database in Fig. 2(c), it can be seen that the feeling of stiffness of the mandibular bone describe by the clinician is the lower part of the bone which is the depth of more than about $4 \mathrm{~mm}$. What is interesting in this data is that the feeling of stiffness for the samples shifted according to their experiences accumulated while doing an actual surgery. The more experienced clinician felt that the database's sample is stiffer than his average force felt while drilling in an actual surgery.

In the students' evaluation, they are asked to sketch the drilling force versus the depth curve of Sample $\mathrm{C}$ by comparing it with the other samples as shown in Fig. 4. Based on Sample C, a total of 9 point of interest were taken and evaluated for each of the students sketch. The students sketch varies between individual and most of them move along Sample C curve line from the upper left to the lower right as shown in Fig 6(a). As shown in Table 1, all students $(100.0 \%)$ could recognize the feeling of perforation when the drill enters the trabecular bone region and almost all of the students $(91.7 \%)$ could recognize the force difference between the upper and lower region and most of them, which is about $79.2 \%$, could identify the difference of high drilling force required, which is about $5 \mathrm{~N}$. By comparing it with Sample B, most of them (83.3\%) could recognize that the drilling force in the upper region of Sample C is actually much higher. Interestingly, a few students, which is about $37.5 \%$ of them, could feel the zigzag curve in the upper region although its force difference is very slight, which is only around $1 \mathrm{~N}$.

\section{Discussion}

The discussion of the results begins with the combination of drilling speed or insertion speed while drilling through the mandibular bone and force found during the clinicians' evaluation. The combination of the speed and force during drilling is interesting because by comparing Fig. 3 and Fig. 5, the feeling shown and the quantitative value obtained seems to be not correlated to each other. Although Clinician 6 could feel that the bone is much softer than Clinician 8 , the drilling speed value in Fig. 5(a) shows otherwise. The drilling speed value of Clinician 6 is much faster than Clinician 8 and even Clinician 4. But in Fig. 5(b), by comparing Clinician 6 drilling different samples, the drilling speed somewhat corresponds properly with the stiffness felt. Therefore, the combination of these two values seem to be one of the methods to quantify the drilling force sensed based on the positive comments received from the experienced clinicians using the training simulator. The realistic feeling describe by the clinicians suggest that the output information of drilling force and speed is highly reliable and valid for further discussion on quantifying the drilling force sensed. The experienced gained from doing an actual surgery and comparing it with the training simulator and its database provides evidence of the system validity.

In addition, to the best of our knowledge, the present study is the first one to suggest the force sensed from drilling the trabecular bone in oral implant surgery is the correlation of drilling force and speed. We expanded the quantitative study by doing the evaluation on a group of students in dental college. Since the students do not have any experience of handling an actual surgery, we asked them to drill the two different samples to establish a baseline of average drilling force felt. The required drilling force curves are also revealed to them to make sure their understanding of stiffness felt is quantified based on the calculation of drilling force. As a result, in comparison with Sample A and B, Fig. 6(b) and 6(c) show some of the typical sketches drawn by the students. It was surprising that the finding agrees well with the evaluation done on the experienced clinicians. The comparison with previous drilling and the correlation of drilling force and speed seems to be the highlights of this study to quantify the drilling force sensed.

Among the plausible explanations for these findings is that the user could understand the force sensed based on relative value of the difference of reaction force during drilling obtained by accumulated experience of drilling a wide range of drilling force database or doing an actual surgery. These finding indicates that the relative value is the key parameter in order to understand more about the drilling process. The relative value could change based on experiences and provide a more long term effect in order tackle the problem occurred during oral implant surgery.

In general, by highlighting the sensing of slight force change of $1 \mathrm{~N}$, it was difficult even for experienced clinicians throughout this research. However, based on the students' evaluation, the findings suggest that about one-third of them could recognize the slight change. One of the reasons known is probably due to the high force the slight change occurs. 
Bin Kamisan, Kinoshita, Nakamura, Homma, Yajima, Matsunaga, Abe and Takano, Journal of Biomechanical Science and Engineering, Vol.11, No.3 (2016)

The zigzag change happens at a very high force of about $7 \mathrm{~N}$. Because of that, the students gave large force to drill and it seems that it is easier to recognize the slight change of force if larger force is given to the handpiece. On the contrary, in the experienced clinicians' evaluation, Clinician 4 in Fig. 3 could actually recognize the slight force change of $1 \mathrm{~N}$ for Sample $\mathrm{A}$ at the average force level of $2 \mathrm{~N}$ as shown in Fig. 2(c), although he did not give a large force to drill Sample A.

Furthermore, during this research, the developed simulator was also used for senior clinicians (with an average age of 54 years old) at a seminar organized by Tokyo Dental Association. Surprisingly, in this seminar it was found that the drilling force sensed was apparently dependent on the type of handpiece. That is, the total weight, the position of the center of gravity and so on influenced the force felt when drilling. The merit of the developed simulator and the importance of using a real handpiece were revealed. Very roughly speaking, heavier handpiece was easier to get precise force sensed. But, further study is needed about the correlation of the force sensed and the type of handpiece quantitatively, which is expected to improve the handpiece for better force sensing.

Apart from that, according to the National Health Institute of Health (NIH) Consensus Development Panel on Osteoporosis Prevention, Diagnosis, and Therapy, the bone strength is affected by bone quality thus the present findings could be one of the parameter in order to provide quantitative information on bone quality since bone quality is highly related with the drilling process.

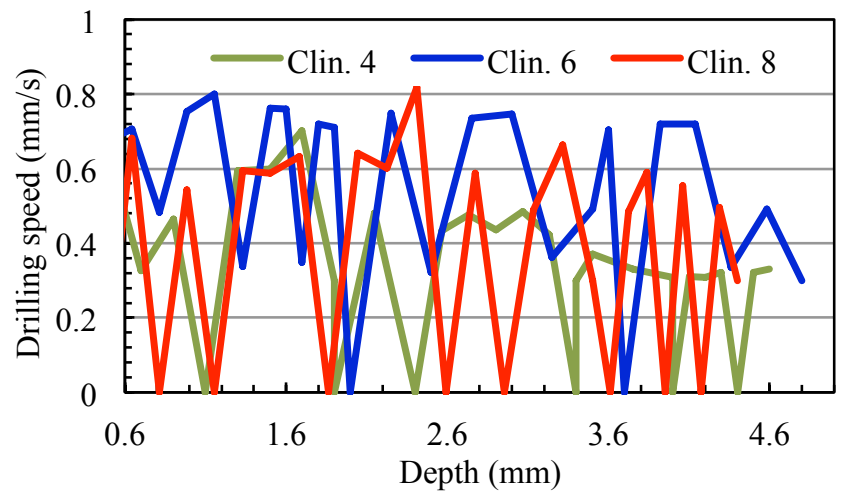

(a) Comparison of Clinician 4, 6, and 8 drilling Sample A

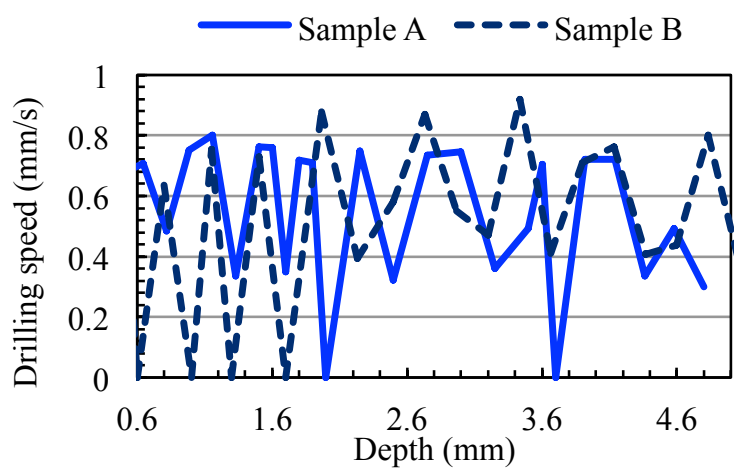

(b) Comparison of Sample A and B drilled by Clinician 6

Fig. 5 Drilling speed obtained from the evaluation done on the clinicians in the trabecular bone region

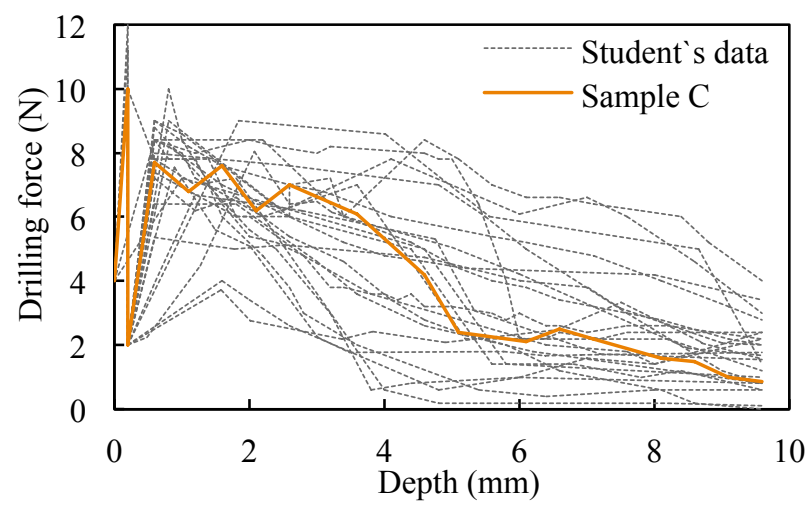

(a) Comparison of all students' sketch with Sample C

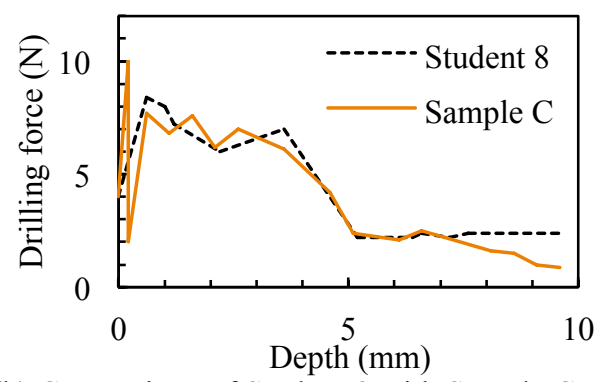

(b) Comparison of Student 8 with Sample C

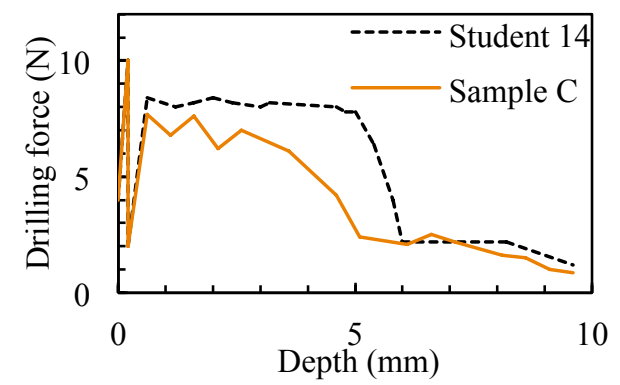

(c) Comparison of Student 14 with Sample C

Fig. 6 Result from the students' evaluation. (a) Comparison of all the students' sketch with Sample C and some of the typical cases sketch by (b) Student 8 and (c) Student 14 in comparison with Sample 4 
Bin Kamisan, Kinoshita, Nakamura, Homma, Yajima, Matsunaga, Abe and Takano, Journal of Biomechanical Science and Engineering, Vol.11, No.3 (2016)

\section{Conclusion}

This paper presented the results of evaluation of the clinicians and also students of dental college based on their usage of the oral implant surgery training simulator. The training simulator was purposely planned to be introduced as an education system based on comments and evaluation done. The previous study (Kinoshita et al., 2016) was the first step involving dentist in the training simulator development by doing an evaluation on the characteristic of the mandibular bone felt during drilling such as the sudden drop of force felt when the drill penetrated the upper cortical bone. The present study was an expansion of the project to understand more about the drilling process from the mechanical point of view by quantifying the force sensed. This study has shown that the quantification of force sensed during oral implant surgery is derived from the combination and correlation of drilling force and speed. These could be obtained through the relative value by comparing with the previous or accumulated experience of the drilling process regardless of the actual surgery. Other than that, these findings enhance our understanding of the bone quality especially in oral implant so a further study investigating the quantification of force sensed based on correlation of drilling force and speed would be very interesting. The training simulator shows great potential as the user could increase their level of proficiency and learn the difference of drilling force sense dependent on the bone quality through repeated usage and practices.

\section{Acknowledgment}

This work has been supported by JSPS KAKENHI (Grant-in-Aid for Challenging Exploratory Research, $15 \mathrm{~K} 13837)$

\section{References}

Albrektsson T., Sennerby L., and Wennerberg A., State of the art of oral implants, Periodontology 2000, Vol. 47, No. 1, (2008), pp.15-26.

Augustin G., Davila S., Mihoci K., Udiljak T., Vedrina D.S., and Antabak A., Thermal osteonecrosis and bone drilling parameters revisited, Archives of Orthopedic Trauma Surgery, Vol. 128, No. 1, (2008), pp.71-77.

Chen X., Lin Y., Wang C., Wu Y., Wang X., and Shen G., An integrated surgical planning and virtual training system using a force feedback haptic device for dental implant surgery, Proceedings of 2010 International Conference on Audio, Language and Image Processing (ICALIP 2010), Article No. 5685115, pp.1257-1261.

Chen X., Lin Y., Wang C., Shen G., and Wang X., A virtual training system using a force feedback haptic device for oral implantology, Lecture Notes in Computer Science (including subseries Lecture Notes in Artificial Intelligence and Lecture Notes in Bioinformatics) during 6th International Conference on E-Learning and Games, Edutainment 2011, (2012), Vol 7220 LNCS, pp.232-240.

Chrcanovic B.R., Albrektsson T., and Wennerberg A., Reasons for failures of oral implants, Journal of Oral Rehabilitation, Vol. 41, No. 6, (2014), pp.443-476.

De Bruyn H., Koole S., Mattheos N., and Lang N.P., A survey on undergraduate implant dentistry education in Europe, European Journal of Dental Education, Vol. 13 Suppl. 1, (2009), pp.3-9.

Donos N., Mardas N., and Buser D., An outline of competencies and the appropriate postgraduate educational pathways in implant dentistry, European Journal of Dental Education, Vol. 13 Suppl. 1, (2009), pp.44-54.

Friberg B., Sennerby L., Roos J., and Lekholm U., Identification of bone quality in conjunction with insertion of titanium implants. A pilot study in jaw autopsy specimens, Clinical Oral Implants Research, Vol. 6, No. 4, (1995), pp.213-219.

Kim S.J., Yoo J., Kim Y.S., and Shin S.W., Temperature change in pig rib bone during implant site preparation by low-speed drilling, Journal of Applied Oral Sciences, Vol. 18, No. 5, (2010), pp.522-557.

Kinoshita H., Nagahata M., Takano N., Takemoto S., Matsunaga S., Abe S., Yoshinari M., and Kawada E. Development of a drilling simulator for dental implant surgery, Journal of Dental Education, (2016), in press.

Kroeplin B.S., and Strub J.R., Implant dentistry curriculum in undergraduate education: part 1-a literature review, The International Journal of Prosthodontics, Vol. 24, No. 3, (2011), pp.221-234. 
Kusumoto N., Sohmura T., Yamada S., Wakabayashi K., Nakamura T., and Yatani H., Application of virtual reality force feedback haptic device for oral implant surgery, Clinical Oral Implants Research, Vol. 17, No. 6, (2006), pp.708-713.

Limbert G., van Lierde C., Muraru O.L., Walboomers X.F., Frank M., Hansson S., Middleton J., and Jaecques S., Trabecular bone strains around a dental implant and associated micromotions--a micro-CT-based three-dimensional finite element study, Journal of Biomechanics, Vol. 43, No. 7, (2010), pp.1251-1261.

Mattheos N., Albrektsson T., Buser D., De Bruyn H., Donos N., Hjørting Hansen E., Lang N.P., Sanz M., and Nattestad A., Teaching and assessment of implant dentistry in undergraduate and postgraduate education: A European consensus, European Journal of Dental Education, Vol. 13 Suppl. 1, (2009), pp.10-17.

Mattheos N., Wismeijer D., and Shapira L., Implant dentistry in postgraduate university education. Present conditions, potential, limitations and future trends, European Journal of Dental Education, Vol. 18, Suppl. 1, (2014), pp.2432.

Melo M.D., Shafie H., and Obeid G., Implant survival rates for oral and maxillofacial surgery residents: a retrospective clinical review with analysis of resident level of training on implant survival, Journal of Oral and Maxillofacial Surgery, Vol. 64, No. 8, (2006), pp.1185-1189.

Osteoporosis prevention, diagnosis, and therapy, NIH Consensus Statement 2000, Vol. 17, No. 1, pp.1-36, https://consensus.nih.gov/2000/2000osteoporosis111html.htm

Reporting of Emergency Survey on Serious Medical Trouble Related to Implant Surgery (Preliminary), Japan Academy of Maxillofacial Implant, (2012), (in Japanese).

Rhienmora P., Haddawy P., Khanal P., Suebnukarn S., and Dailey M.N., A virtual reality simulator for teaching and evaluating dental procedures, Methods of Information in Medicine, Vol. 49, No. 4, (2010), pp.396-405.

Sugaya K., Study on method for examining bone quality for dental implant. Relationship between cutting force and bone mineral content, Shikwa Gakuho, Vol. 90, No. 4, (1990), pp.607-633 (in Japanese).

Tawara D., Nagahata M., Takano N., Kinoshita H., and Abe S., Probabilistic analysis of mechanical behaviour of mandibular trabecular bone using a calibrated stochastic homogenization model, Acta Mechanica, Vol. 226, No. 10, (2015), pp.3275-3287.

Temmerman A., Meeus M., Dhondt R., Wienrinck E., Teughels W., Naert I., and Quirynen M., Oral implant placement and restoration by undergraduate students: clinical outcomes and students perceptions, European Journal of Dental Education, (2015), DOI: 10.1111/eje.12144.

Ucer T.C., Botticelli D., Stavropoulos A., and Mattheos N., Current trends and status of continuing professional development in implant dentistry in Europe, European Journal of Dental Education, Vol. 18 Suppl. 1, (2014), pp.52-59.

Zheng F., Lu W.F., Wong Y.S., and Foong K.W.C., An analytical drilling force model and GPU-accelerated haptics-based simulation framework of the pilot drilling procedure for micro-implants surgery training, Computer Methods and Programs in Biomedicine, Vol. 108, No. 3, (2012), pp.1170-1184.

Zheng F., Lu W.F., Wong Y.S., and Foong K.W.C., Graphic processing units (GPUs)-based haptic simulator for dental implant surgery, Journal of Computing and Information Science in Engineering, Vol. 13, No. 4, (2013), Article No. 041005 . 